Methods: Twenty- two individuals with APS with or without other associated autoimmune disease (20 females, two males, median age 55 (range 18-70) years) had blood samples taken before and 12 weeks after starting HCQ 200mg. Plasma was stored at $-80^{\circ} \mathrm{C}$ and thawed to measure TF using Imubind TF kit (Invitech Ltd, Cambridgeshire, UK). The assay was performed according to the manufacturer's instructions. Patient characteristics are outlined in table 1. Statistical analysis was performed using SPSS Version 22. For continuous normally distributed data a two-tailed student's paired t-test was performed. A value of $p=0.05$ was considered as significant. There are no previous data in this area, so we were unable to do a power calculation to work out study size. Our study is therefore a pilot study.

Results: Soluble TF levels were above our normal range $(40-300 \mathrm{pg} / \mathrm{ml})$ prior to the commencement of $\mathrm{HCQ}$ and were significantly reduced (pre level mean (SD) $401.8(152.8) \mathrm{pg} / \mathrm{ml}$ versus post 300.9 (108) $\mathrm{pg} / \mathrm{ml}(\mathrm{p}=0.010)$.

\begin{tabular}{|c|c|}
\hline Variables & APS $(\mathrm{N}=22)$ \\
\hline Age: median (range) & $47(18-69)$ \\
\hline Sex (female:male) & 20:02 \\
\hline Ethnicity (white:asian:black) & $(20: 1: 1)$ \\
\hline \multicolumn{2}{|l|}{ aPL subtype } \\
\hline LA* positive & 19 \\
\hline IgG or IgM aCL positive (>99th centile) & 5 \\
\hline \multirow{2}{*}{\multicolumn{2}{|c|}{$\begin{array}{l}\text { IgG or IgM anti-Beta2GPI antibody positive (>99th } \\
\text { centile) }\end{array}$}} \\
\hline & 0 \\
\hline $\mathrm{aCL}$ and anti-Beta2GPI antibody positive (>99th centile) & 0 \\
\hline aCL antibody and LA* positive (>99th centile) & 3 \\
\hline $\begin{array}{l}\text { Anti-Beta2GPI antibody and LA* positive (>99th } \\
\text { centile) }\end{array}$ & 0 \\
\hline \multicolumn{2}{|l|}{ aPL complication } \\
\hline \multicolumn{2}{|l|}{ Thrombosic APS } \\
\hline Previous arterial thrombosis & 10 \\
\hline Previous venous thrombosis & 7 \\
\hline Previous arterial and venous thromboses & 4 \\
\hline \multicolumn{2}{|l|}{ Obstetric APS } \\
\hline Previous recurrent 1st trimester pregnancy loss & 2 \\
\hline Previous pre-eclampsia & 1 \\
\hline Previous intrauterine growth restriction & 1 \\
\hline Previous stillbirth & 3 \\
\hline \multicolumn{2}{|l|}{ Treatment } \\
\hline Warfarin & 14 \\
\hline Heparin & 0 \\
\hline Aspirin & 3 \\
\hline \multicolumn{2}{|l|}{ Autoimmune profile } \\
\hline Antinuclear antibodies (ANA) & 10 \\
\hline Extractable nuclear antibodies (ENA) & 2 \\
\hline Double stranded DNA antibodies (dsDNA) & 1 \\
\hline
\end{tabular}

Conclusions: There was a significant reduction in soluble TF levels in this patient cohort of patients with apL and APS after commencing HCQ. Our previous work has shown that HCQ has not affected complement turnover, VEGF levels, thromboelastometry findings or CRP levels. Our findings of a reduction of soluble TF levels in aPL positive patients after the commencement of HCQ maybe a key mechanism by which $\mathrm{HCQ}$ reduces thrombotic risk. Further studies of a larger patient cohort are required to confirm our observation.

References:

[1] Miyakis, S., et al., International consensus statement on an update of the classification criteria for definite antiphospholipid syndrome (APS). J Thromb Haemost, 2006. 4(2): p. 295-306.

Disclosure of Interest: K. Schreiber Shareholder of: Novo Nordisk, Grant/research support from: educational support from Daiichi Sankyo, K. Breen: None declared, K. Parmar: None declared, B. Hunt: None declared DOI: 10.1136/annrheumdis-2017-eular.4746

\section{AB0148 INDUCTION OF HO-1 EXPRESSION IN MONOCYTES MIGHT PREVENT KIDNEY DAMAGE IN LUPUS NEPHRITIS (LN)}

L. Cuitino $^{1}$, J. Obreque ${ }^{1}$, P. Gajardo-Meneses ${ }^{1}$, N. Crisostomo ${ }^{1}$, A. Torres ${ }^{1}$, A.M. Kalergis ${ }^{2}$, C. Llanos ${ }^{1} .{ }^{1}$ Departamento de Inmunologia Clinica y Reumatologia; ${ }^{2}$ Millennium Institute on Immunology and Immunotherapy, Departamento de Endocrinologia, Pontificia Universidad Catolica de Chile, Santiago, Chile

Background: Systemic lupus erythematous (SLE), is an autoimmune disease characterized by autoantibody synthesis and inflammation. During disease course, up to $70 \%$ of SLE patients will develop LN. Emerging evidence has demonstrated that infiltrating monocytes and macrophages are associated with LN pathogenesis. We have previously demonstrated that $\mathrm{HO}-1$, a haem-degrading enzyme with anti-inflammatory properties is decreased in peripheral monocytes of SLE patients. Therefore, we decided to explore the contribution of HO-1 expression to LN pathogenesis.
Objectives: To explore the role of $\mathrm{HO}-1$ in modulating innate immunity through a cytoprotective effect in monocytes of LN nephritis patients. Accordingly, we examined the expression of $\mathrm{HO}-1$ in circulating monocytes, and the effect of $\mathrm{HO}-1$ induction in reactive oxygen species (ROS) production and the phagocytic activity of monocytes from peripheral blood of LN patients and healthy controls $(\mathrm{HC})$.

Methods: SLE patients with proliferative LN confirmed by renal biopsy (Class III, IV or V ISN/RPS) were recruited at Hospital Clinico of PUC. All individuals signed an informed consent form. Monocytes were purified from peripheral blood mononuclear cells (PBMCs) of LN patients and HC using pan-monocytes MACS kit. Subpopulations of monocytes and $\mathrm{HO}-1$ expression were measured by FACS. ROS was determined using CellRox Kit. The phagocytic ability of monocytes was assessed by FACS and the total phagocytosis was calculated as the percentage of cells with engulfed beads.

Results: We found that monocytes from LN patients show significant differences when compared to $\mathrm{HC}$ in all the parameters analyzed. The percentage of CD16+ inflammatory monocytes was higher in $\mathrm{LN}$ patients $(6.72 \pm 0.98 \%)$ compared to $\mathrm{HC}(4.07 \pm 0.48 \%)(\mathrm{p}<0.05)$. $\mathrm{HO}-1$ protein expression is decreased in circulating LN monocytes $(4789 \pm 911$ vs $1572 \pm 481, p=0.005)$. Baseline levels of ROS are elevated in LN monocytes with similar values that the ones found in monocytes from HC treated with a ROS inducer (HC: 3509 \pm 584 ; HC+TBHP: $8436 \pm 1909$; $\mathrm{LN}: 8355 \pm 1714)$. Furthermore, phagocytic activity is increased in LN monocytes $(77.97 \pm 3.31 \%)$ compared to $\mathrm{HC}(39.63 \pm 2.75 \%)$. Moreover, our preliminary data indicate that $\mathrm{HO}-1$ induction, using cobalt protoporphyrin (CoPP), leads to downregulation of ROS production in $\mathrm{LN}(\sim 60 \%)$ and $\mathrm{HC}(\sim 40 \%)$ leaving both in similar levels of ROS production. In addition, phagocytic activity is also decreased in $\mathrm{LN}$ and $\mathrm{HC}$ monocytes in the presence of CoPP $(\sim 30 \%)$.

Conclusions: Decreased HO-1 expression in circulating monocytes of LN patients leads to higher ROS production and phagocitic activity. ROS level and phagocytosis are reduced when we induce $\mathrm{HO}-1$ expression with CoPP. We propose that $\mathrm{HO}-1$ induction might exert a cytoprotective role in $\mathrm{LN}$ by regulating innate immunity. FONDECYT N¹150173.

Acknowledgements: We would like to extend our appreciation to all the volunteers that participated in this study.

Disclosure of Interest: None declared

DOI: 10.1136/annrheumdis-2017-eular.6428

\section{AB0149 PROLACTIN AND AUTOPHAGY IN SYSTEMIC LUPUS ERYTHEMATOSUS: CLINICAL SIGNIFICANCE OF CORRELATION BETWEEN PRL-R+ (RECEPTOR), CD19+, ATG14+, AND CD25+ EXPRESSION ON B AND T REGULATORY CELLS}

L. Jara ${ }^{1}$, E. Zurita ${ }^{2}$, A. Durán ${ }^{3}$, G. Medina ${ }^{1}$, C. Arroyo ${ }^{4}$, M.A. Saavedra ${ }^{5}$, A. Sanchez ${ }^{5}$, R. Bustamante ${ }^{5}$, A. Rodriguez ${ }^{3}$. ${ }^{1}$ Direction of Education and Research, Instituto Mexicano del Seguro Social, Hospital de Especialidades Centro Medico la Raza; ${ }^{2}$ Escuela Nacional de Ciencias Biologicas, Institutu\}o Politecnico Nacional; ${ }^{3}$ Escuela Nacional de Ciencias Biologicas, Instituto Politecnico Nacional; ${ }^{4}$ Banco de Sangre Hospital de Especialidades Centro Medico la Raza; ${ }^{5}$ Rheumatology Department, Instituto Mexicano del Seguro Social, Hospital de Especialidades Centro Medico la Raza, Mexico City, Mexico

Background: Systemic Lupus Erythematosus (SLE) is a prototype of autoinmune diseases with excessive anti-nuclear autoantibodies production. B cells activation with immune complex formation is the main characteristic of SLE with abnormalities in immune cells, dysregulation of apoptosis, and defects in the clearance of apoptotic materials. Autophagy, a highly conserved protein degradation pathway, is essential for removing protein aggregates and misfolded proteins in cells and its defects contributes to SLE pathogenesis. On the other hand, multiple evidences in humans and experimental models suggest that prolactin (PRL) is associated with active SLE and participates in the immune dysregulation, and one of the mechanisms of PRL action is the inhibition of apoptosis.

Objectives: Analyze the relationship between $P R L$ receptors (PRL-R) on $B$ cells and markers of autophagy on $T$ regulatory cells and the association, if any, with clinical characteristics of SLE.

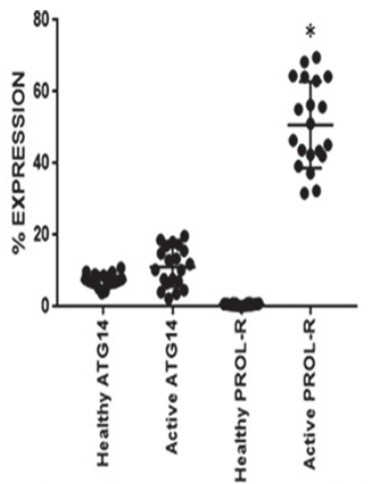

Expresssion of PRL-R and ATG14 in active SLE patients and healthy controls. ${ }^{z} p=0.026$ Dunn's multiple comparisons test. 
Methods: The expression of PRL-R on B cells $\mathrm{CD} 19^{+}$, and autophagy-related key regulator protein $\mathrm{ATG}_{14} 4^{+}$, on $\mathrm{T}$ regulatory cells $\mathrm{CD} 25^{+}$, were measured by flow cytometry, and expressed in percentages of SLE patients (1997, ACR criteria), and healthy controls. Active SLE was considered by SLEDAI $(\geq 4)$. The organs affected and treatments were evaluated.

Results: A total of 40 SLE patients and 20 healthy controls were included. Mean age of patients and controls was $30.67 \pm 4.16$. Mean duration of disease was $6 \pm 4.6$ years. Twenty patients were active (SLEDAI $8.45 \pm 1.9$ ) and of these, lupus glomerulonephritis was observed in 13 patients $(65 \%)$. The expression of PRL-R on B cells of active SLE was higher than in inactive SLE (50.5\% vs $26.5 \%)$. In active SLE especially in patients with glomerulonephritis, the mean amount of PRL-R on B cells $/ \mathrm{ml}$ was $6,645 / \mathrm{ml}$ (range 3167-6957). In contrast, patients with inactive SLE, had a low amount of PRL-R, 522.5/ml (range 15-895). In the relation of autophagy, the mean expression of ATG14+ in 20 active SLE patients was $11.19 \%$ in comparison with inactive SLE patients, $7.13 \%,(p=0.04)$, and in healthy donors, $7.445 \%(p=0.0281)$

Conclusions: Our study suggest: In active SLE patients the expression of PRL-R and autophagy-related key regulator protein ATG14+ are very high in B cells and $T$ regulators respectively, in comparison with inactive SLE and healthy donors. These novel findings suggest the interaction between PRL-R and autophagy in order to promote clinical/immune activation with overproduction of autoantibodies. PRL-R and ATG14+ may be a new target of SLE treatment.

\section{References:}

[1] Lech M, Anders HJ, The pathogenesis of lupus nephritis. J Am Soc Nephrol, 2013, 24, 1357-1366.

[2] Jara LJ, Medina G, Saavedra MA, et al. Prolactic has a patogenyc role in systemic lupus erythematosus, Inmmunol Res, 2017, Jan 28.

Disclosure of Interest: None declared

DOI: 10.1136/annrheumdis-2017-eular.6887

\section{AB0150 INCREASED ERYPTOSIS LEVELS IN PRIMARY ANTIPHOSPHOLIPID SYNDROME PATIENTS}

M. Vomero ${ }^{1}$, F. Ceccarelli ${ }^{1}$, A. Finucci ${ }^{1}$, C. Pensa ${ }^{1}$, C. Barbati ${ }^{1}$, T. Colasanti ${ }^{1}$, F.R. Spinelli ${ }^{1}{ }^{1}$, L. Massaro ${ }^{1}$, S. Truglia ${ }^{1}$, C. Perricone ${ }^{1}$, F. Miranda ${ }^{1}$, F.R. Mauro ${ }^{2}$, R. Foà ${ }^{2}$, F. Conti ${ }^{1}$, G. Valesini ${ }^{1}$, C. Alessandri ${ }^{1} .{ }^{1}$ Department of Internal Medicine and Medical Specialties, Lupus Clinic, Sapienza University of Rome; ${ }^{2}$ Department of Cellular Biotechnologies and Hematology, Hematology, Sapienza University of Rome, Rome, Italy

Background: Erythrocytes (RBCs) hold a crucial role in hemostasis and their integrity is influenced by different stimuli including circulating inflammatory mediators. Even though RBCs do not have nuclei and mitochondria, they have developed a process allowing them to undergo a rapid self-destruction named eryptosis. The exact mechanism of erythrocytes cell death is not fully clarified yet but it seems to involve $\mathrm{Ca}^{2+}$ and ceramide formation, leading to cell shrinkage and externalization of phosphatidylserine (PS) (1). Interaction between platelets and erythrocytes could participate in an increasing risk of thrombotic episodes typical of several diseases including antiphospholipid syndrome (APS). In fact, not only signals triggering eryptosis are involved in thrombosis activation, but also recent studies have demonstrated how PS-exposing erythrocytes are able to adhere to the vascular wall causing an impairment of circulation $(2,3)$.

Objectives: Enhanced eryptosis is known to contribute to several pathological conditions (1) but the involvement of this process in APS has not been investigated yet. For this reason the aim of the study was to evaluate eryptosis levels in APS, healthy subjects positive for antiphospolipid antibodies without clinical manifestations (aPL carriers), autoimmune haemolytic anaemia (AIHA) and healthy donors (HD).

Methods: 27 patients with primary APS ( $M / F 5 / 22$, mean age $51.1 \pm 7.6$ years), $14 \mathrm{aPL}$ carriers (M/F $3 / 11$, mean age $48.9 \pm 8.4$ years) were recruited after written informed consent. Moreover 10 AlHA patients and $12 \mathrm{HD}$ were also enrolled as positive and negative control group respectively. RBCs were isolated from whole blood after centrifugation and eryptosis levels were analysed by flow cytometry, evaluating the percentage of annexin V-positive cells (PS-exposing cells). Flow cytometry was also use to estimated cellular volume from forward scatter (FSC). Results: APS patients showed higher levels of eryptosis compared to HD $(p=0.01)$. Interestingly, the percentage of annexin V-positive RBCs was lower in aPL carriers respect to APS patients $(p=0.001)$. Moreover, an inverse correlation between RBCs volume and eryptosis was found in APS patients $(r=-0.4, p=0.03)$. No clinical correlation between eryptosis and clinical manifestations were noticed. As expected, eryptosis was upregulated in AlHA patients compared to all populations studied $(p<0.0001)$.

Conclusions: Our study provides for the first time evidence of eryptosis enhancement in APS patients suggesting a possible contribution of RBCs apoptosis in the pathogenesis of the disease.

References:

[1] Lang E, Lang F. Triggers, inhibitors, mechanisms, and significance of eryptosis: the suicidal erythrocyte death. Biomed Res Int. 2015;2015:513518.

[2] Borst O, Abed M, Alesutan I, Towhid ST, Qadri SM, Foller M, Gawaz M, Lang F. Dynamic adhesion of eryptotic erythrocytes to endothelial cells via CXCL16/SR-PSOX. Am J Physiol Cell Physiol. 2012;302:C644-C651.

[3] Pretorius E, du Plooy JN, Bester J. A Comprehensive Review on Eryptosis. Cell Physiol Biochem. 2016;39:1977-2000.

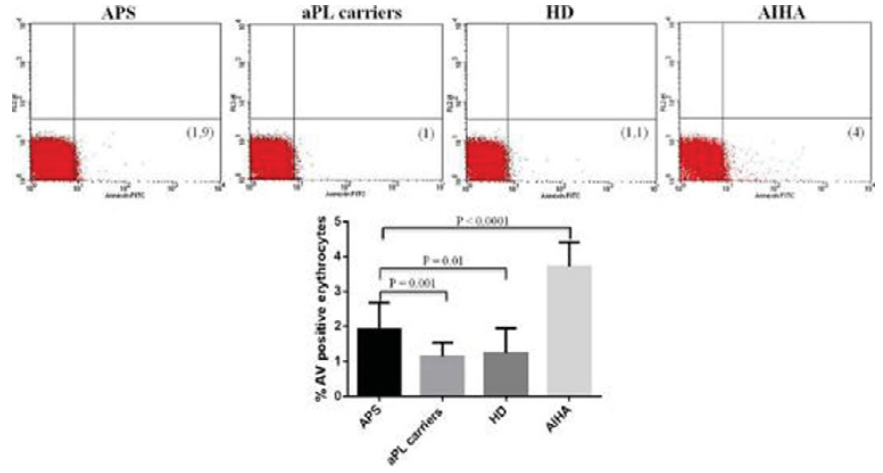

Disclosure of Interest: None declared

DOI: 10.1136/annrheumdis-2017-eular.4734

\section{AB0151 STRESS MODERATION IMPACTING LUPUS WITH EXERCISE (S.M.I.L.E.): INFLUENCE OF DAILY MODERATE EXERCISE AND STRESS MODIFICATION ON AUTOIMMUNE-MEDIATED INFLAMMATION IN MICE AND HUMANS WITH LUPUS}

N.A. Young ${ }^{1}$, E. Thomas ${ }^{1}$, B. Snoad ${ }^{1}$, J. Sharma ${ }^{1}$, M. Mobeen ${ }^{1}$,

J. Yedimenko ${ }^{1}$, H. Steigelman ${ }^{1}$, A. Meara ${ }^{1}$, G. Valiente ${ }^{2}$, S. Ardoin $^{1}$,

N. Powell ${ }^{3}$, J. Sheridan ${ }^{3}$, W. Jarjour ${ }^{1} .{ }^{1}$ Rheumatology and Immunology;

${ }^{2}$ Medical Oncology; ${ }^{3}$ Institute for Behavioral Medicine Research, The Ohio State University Wexner Medical Center, Columbus, United States

Background: Despite numerous studies indicating the positive effects of exercise and psychological stress reduction in patients with autoimmune disease, these therapeutic modalities are currently underemphasized due to the absence of comprehensive immunological characterization and regimen standardization.

Objectives: In order to examine the influence on the immune system at the cellular and tissue level, disease pathology was analyzed in the NZM2410 mouse model of lupus nephritis. To translate these results and begin to characterize a consensus treatment regimen, a pilot cohort of systemic lupus erythematosus (SLE) patients with active disease was enrolled into a daily Tai Chi program, which emphasized moderate exercise levels with meditative breathing to provide daily physical activity and stress reduction.

Methods: Mice were exercised daily by treadmill walking at moderate intensity. Social disruption stress was induced in mice by disturbing the social order within an established hierarchy. All mice were removed from the study when experimental removal criteria was reached [blood urea nitrogen $(\mathrm{BUN})>50 \mathrm{mg} / \mathrm{dL}$; weight loss $>20 \%$ ]. Kidney tissue and serum were collected from mice at experimental endpoint. SLE patients completed daily Tai Chi exercises and data was collected at baseline and throughout the study via questionnaires to access physical activity and stress levels, activity trackers (Fitbit), and serum sample analysis.

Results: Histopathological analysis of NZM2410 mice demonstrated that psychosocial stress induction significantly exacerbated and daily moderate exercise significantly reduced lupus nephritis disease pathology, as measured by BUN levels, complement component 3 and IgG complex deposition in glomeruli, pathological grading of $\mathrm{H} \& \mathrm{E}$-stained kidney sections, and renal macrophage infiltration. Furthermore, stressors induced levels of IL-6, TNF- $\alpha$, and IL-1 $\beta$, while exercise suppressed IL-6, TNF- $\alpha$, IL-10, and CXCL1 in mice. Compared to baseline data, questionnaires confirmed a significant reduction in perceived social stress and an increase in combined metabolic equivalent of task (MET) and overall physical activity in SLE patients. Moreover, fitness activity tracker data showed a significant increase in steps, distance, and activity calories with no changes in body mass index or vigorous activity levels. Interestingly, this correlated with an increased average time in bed each night. Analysis of pro-inflammatory serum cytokine
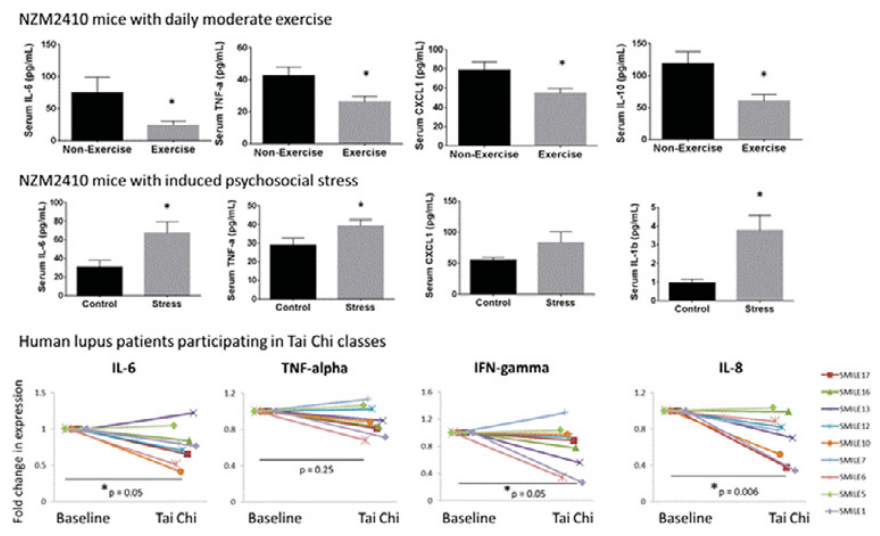